\title{
11 Repurposing a Grocery Store for the Joutsa Public Library in Finland
}

\begin{abstract}
In 2004, the new Joutsa Public Library moved into a renovated former grocery store. Everyone benefitted. The library found a perfect location in the middle of the municipal service centre, which was spared one more sad, empty building. The preparation phase was long and complicated having commenced in 1995. But the renovation phase was quick and took only six months. The building dates from the late 1970s. Few major structural changes were needed to improve the appearance, safety and usability. The result is very flexible with much-appreciated creative shelving solutions and space arrangements. Skilful architects did an excellent job, and the customers find it difficult to believe the origin of the building. The use of the library has increased with greater numbers of customers, increased loans and enhanced event participation justifying the approach taken and demonstrating its success.
\end{abstract}

Keywords: Library buildings ${ }^{1}$ - Design and construction; Public libraries Finland; Sustainability; Grocery trade - Remodelling for other use; Supermarkets - Remodelling for other use

\section{Introduction}

Joutsa is a rural district of 4,400 inhabitants in Central Finland. Joutsa is the central town of the region, which means that the inhabitants of the neighbouring municipalities also use the services. The first library in Joutsa was established by a civil servant responsible for bridges, Aksel Lehtinen, in 1864. The library was not publicly available for everyone but only to the thirty-seven members of a cooperative society. The library was at Lehtinen's home and consisted of some thirty books, mostly on religious topics. Since its establishment, the library has operated in six different places, one being in a church vestry. The new location is the eighth home for the library in Joutsa. And Aksel is still alive today, in the form of a library elf guarding the library from the main desk.

1 Mika Mustikkamäki has contributed significantly to the preparation of the content of this chapter.

2 Open Access. (2021 Nina Kuikka, published by De Gruyter. (c) BY-NC-ND This work is licensed under the Creative Commons Attribution-NonCommercial-NoDerivatives 4.0 International License. 


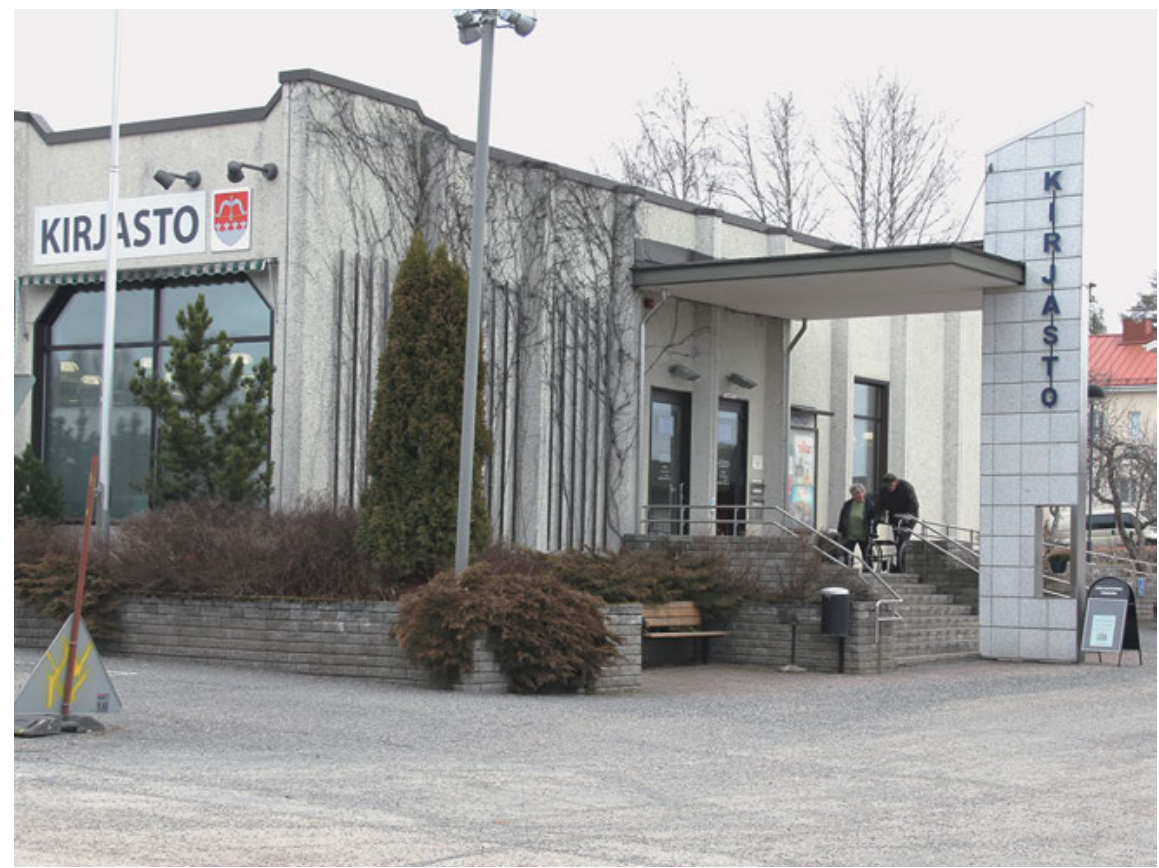

Fig. 1: The Joutsa Public Library moved into a renovated former grocery store from the late 1970s. (C) Eero Peltoniemi.

\section{Facts and Figures}

Name: Joutsa Municipal Library

Address: Länsitie 6, 19650 Joutsa, Finland

Website: https://www.joutsa.fi/vapaa-aika/kirjasto

Opening: October 2004

Builder: Frenta Oy, Jyväskylä

Architects: Kauko Lahti and Jukka S Lehtonen

Gross floor area: $669 \mathrm{~m}^{2}$

Main floor space: $586,5 \mathrm{~m}^{2}$

Collection size: 40,000

Staff: 5

Workstations: 5

Building costs: $€ 1,030,000$ 


\section{The Planning Phase}

Planning the new library was a process that commenced in 1995 and took several years as there were many options to be considered. One possibility was to renovate the old library; another concerned the renovation of a larger building; a third alternative was to build a new cultural and sports centre beside the school. The old library was too small for its renovation to be a seriously considered option and the decision to construct a new building was taken by the majority of members of the municipal council. The ground was bought, an architectural competition organised, and the winning plan chosen. The new municipal council, however, overruled the decision and put the plan on hold. It was thought to be too expensive and the location of the library distant from the municipal centre. The customers meanwhile petitioned the decision makers to locate the library in the centre of Joutsa and the final political decision was to reuse the former grocery store (Figure 2). The location was perfect. An additional advantage was that the building gained a new lease of life. The demise of village centres and even those of smaller towns is an increasing problem worldwide in the $21^{\text {st }}$ century as populations change and services decrease.

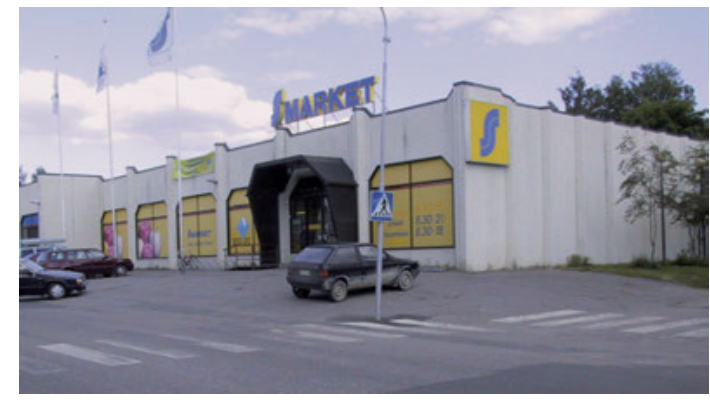

Fig. 2: The former grocery store built in 1978. ( ) Markku Parkkonen.

The grocery store, a flat-roofed, single-storey building with a basement, was built in 1978. In the same building there was also a bank. The architects for the transformation were selected through a call for tenders. The building and its surroundings offered the opportunity to create a pleasant and busy library with the additional advantage of bringing life to the village centre. Various factors had to be considered: the impression on approaching the building from different directions; how easily the purpose and idea of the building could be grasped; and the need for an obvious, welcoming entrance that fitted into its surroundings. First impressions on entering the building are extremely important. Is it attractive, accessible, bright, functional and easy to use? Does it create a pleasant atmo- 
sphere and a desire for users to stay? Many factors contribute to wellbeing and a sense of place and were used in planning the conversion of the building.

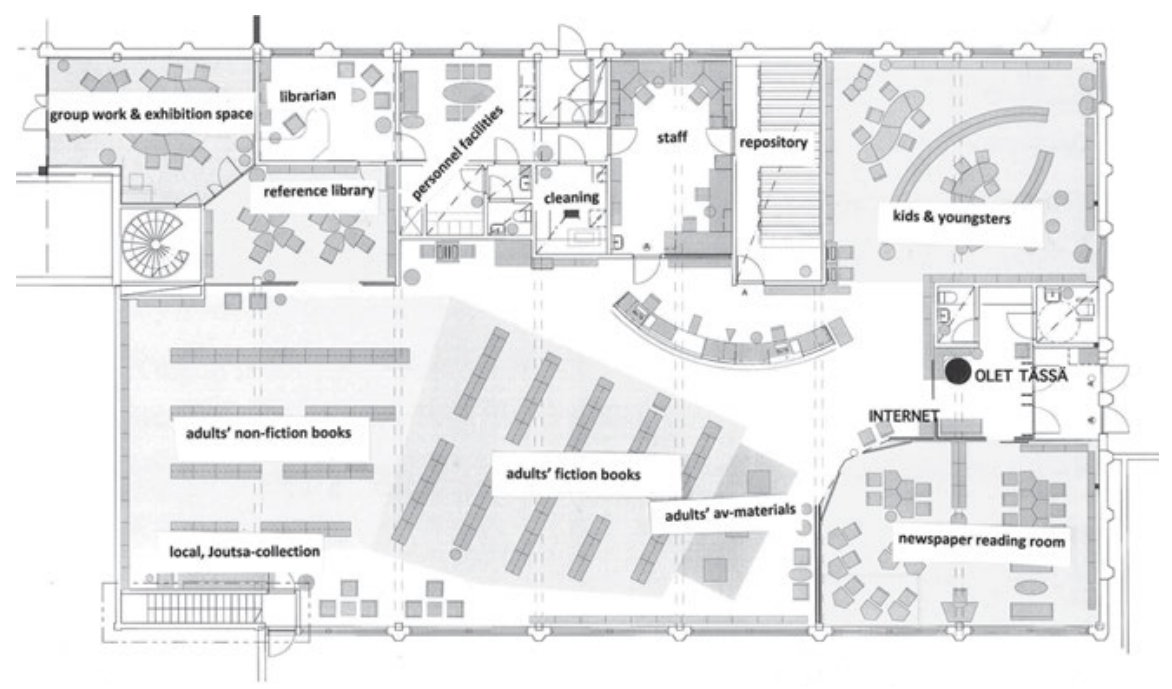

Fig. 3: The floor plan for the new library. @ Joutsa Municipal Library.

\section{Structural Changes}

The grocery store had two entrance doors, the main door at the front and the loading bay door at the back. Moving the main entrance into a safer place on a side street off the main street was the biggest exterior structural change. The new entrance was designed both for functional and aesthetic reasons to be welcoming and to connect with the passing pedestrian area. Extensive excavation was required before the entrance could be relocated to the new position (Figure 4). Another significant external change was to build a low wall and create a garden area between the building and the pavement to improve and soften the appearance of the flat, rather featureless building (Figure 1).

The interior of the grocery store was in good condition. The sewer and subsurface drains had to be checked and repaired as well as the slope of the site. The lack of a decent yard and parking area was problematic and a plan to repair the existing area of the centre came to nothing. However, behind the library is a small apple orchard belonging to a hotel and the library is permitted to use it for different events which eases the situation. 


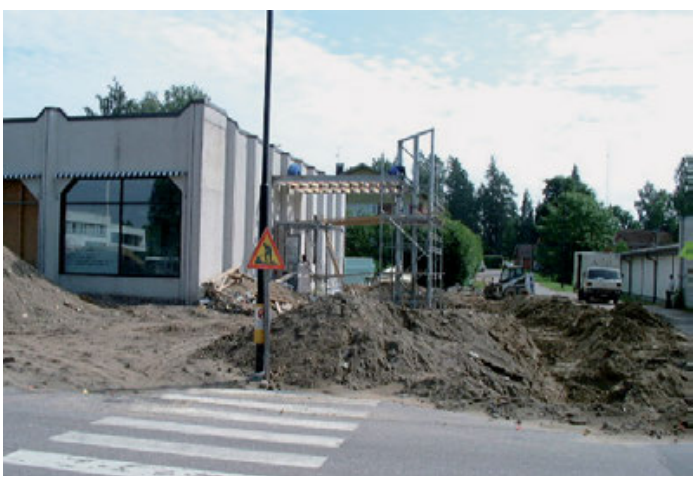

Fig. 4: The biggest external structural change: the main entrance relocated to a safer location in the side street. (c) Eero Peltoniemi.

A new door was provided in the main library area to provide a fire exit and easy access to the basement. A separate staff entrance was created. The storage rooms of the grocery store were converted into staff work areas. Numerous new windows were needed as the former large grocery store windows covered only one wall facing the street. The side and the back walls had no windows. The new windows dramatically changed the appearance of the building, making it lighter and more approachable.

The original street-facing large windows made the interior light and it was possible to install dark shelves which created a warm atmosphere in the large space (Figures 5 and 6). The windows were problematic. Surprisingly, the existing air-conditioning system was not included in the purchase deal and was removed before selling the building to the municipality. The canvas awnings were too small to give the necessary protection against the summer sun and heat, and venetian blinds covering the whole window area were needed. The blinds do not provide the best solution in terms of design and appearance but a better one has not yet been found. It took a couple of years before the new cooling system was installed.

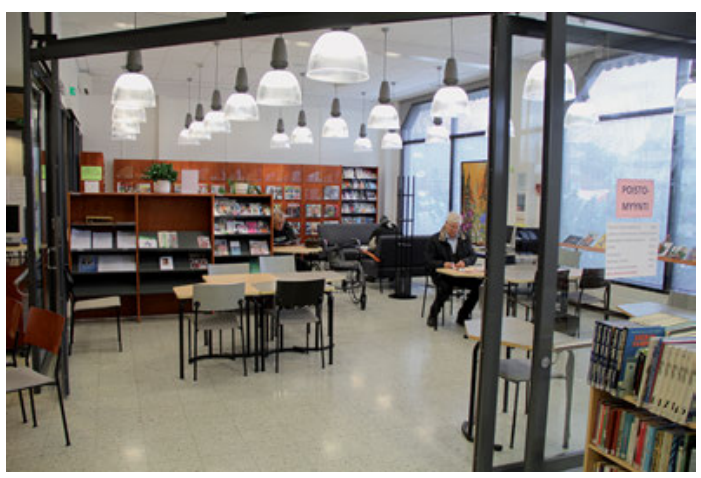

Fig. 5: Newspaper reading room with dark shelving providing warmth in the bright interior. (c) Eero Peltoniemi. 
The inside was completely renovated. Only the floor and the lovely big windows were retained from the former grocery store. The interior was successfully transformed into a warm, welcoming open space for everybody. In this case, it was positive that all evidence of former use was removed as the demands of a grocery store are somewhat different from those of a library; for example, the grocery store was more clinical and less uplifting for soul and spirit. While the building's past use might not have made the best beginning for a library, it offered, even with its disadvantages, a reasonable starting point for a good library solution.

The floor is made of a durable stone and dates to the building of the store in the 1970s. It has worn well and is easy to maintain. The pattern is timeless and the colour light.

The floor plan gives a clear picture of the functions and the room arrangements (Figure 3). Although the main space is large at $315 \mathrm{~m}^{2}$ and has no partitions, the different functions are separated in an innovative way. The shelves are grouped in different zones for adult fiction and non-fiction areas and the main desk area is indicated by a beautiful ceiling finish that gives the interior architectural character (Figure 6).

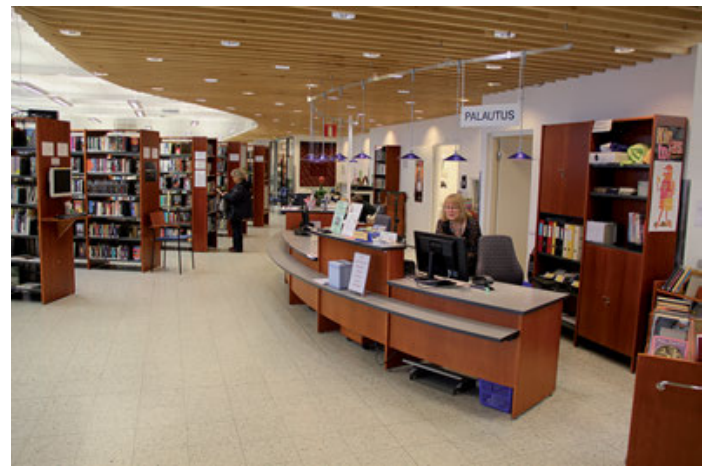

Fig. 6: The main desk area is indicated by a beautiful ceiling. (c) Eero Peltoniemi.

The furnishings in the children's and young adults' department differ from that elsewhere in the library (Figure 7). They are brightly coloured and playful and the arched shelf in the middle is a special and effective divider. Arched forms are a typical motif in the work of the architect Kauko Lahti and have also been used at the main desk.

The newspaper reading room is separated from the rest of the library by glass walls and wide sliding doors (Figure 5). The separation was initially functional because the newspaper area opened earlier than the rest of the library. It is no longer necessary because the whole library has longer opening hours. The 
room was an entrance area to the former grocery store but when the entrance to the library was moved elsewhere, the freed-up space was available to form the reading room. The marketplace is on the opposite side of the street and people reading newspapers feel connected to the life of the street outside.

The loading bay area was turned into an exhibition space. The conversion of the space was an additional expense outside of the original state grant. The local art society was contacted for support and the outcome was that an exhibition room was deemed necessary because there was no suitable venue for the purpose in the centre of the village. The state accepted the additional application and the grant was awarded for the whole area. The exhibition room houses exhibitions which change monthly and are mostly by local artists, amateurs and school classes. Every now and then nationally known travelling exhibitions by bigger names are also shown. The area is situated at the farthest point when viewed from the main entrance which can be seen as either advantageous or problematic. It is advantageous when someone wants to see only the exhibition but must walk through the library and therefore visit it in its entirety. It is problematic however if someone thinks the exhibition is too difficult to find and leaves without visiting it. In the old library, the exhibition room was near the main entrance and more like a gallery space. The space also serves as a meeting room for different groups. Not all problems with reuse can immediately be solved. While the new exhibition space has its own entrance, it cannot easily be used after library opening hours because management of the security system and controlling access in and out of the building are deemed too complex for this option.

\section{The Client Perspective}

The previous library was in an old building formerly used by the Civil Guard and built in 1940. The building was wooden, cosy and beautiful in a traditional way. It embodied valuable cultural history with past functions including a bus station, cinema and the council chambers.

Many library customers, especially holidaymakers from cities, felt quite sad when they heard that the library would get new facilities. They liked the atmosphere, the history and the appearance of the old library. After seeing the new facilities however, nobody continued to long for the old premises. When asked opinions for this chapter an active customer said: "Oh, but I don't remember the old library anymore...”. Another regular user had initially preferred the idea of building the new library near the school but now is happy that it did not eventu- 
ate. The new modern library building has enabled the library service to develop so that today's generation can use it in a way that is appropriate and functional for new needs. In other words, it is fit for purpose in the $21^{\text {st }}$ century.

As well as the larger floor space, the bookshelves and the books have more space. The collection can be displayed in a much better way which matters a lot to the customers. Being able to present books by placing them in a front-facing position showing the covers entices the customers to borrow more. There is also more space for computers which has resulted in increased use. Cosy reading corners and comfortable surroundings ensure that customers enjoy visiting the library and stay longer. Many services are still unknown to the wider public. One elderly lady, after an introductory visit to the library with her group, said: "I feel like Alice in Wonderland!”

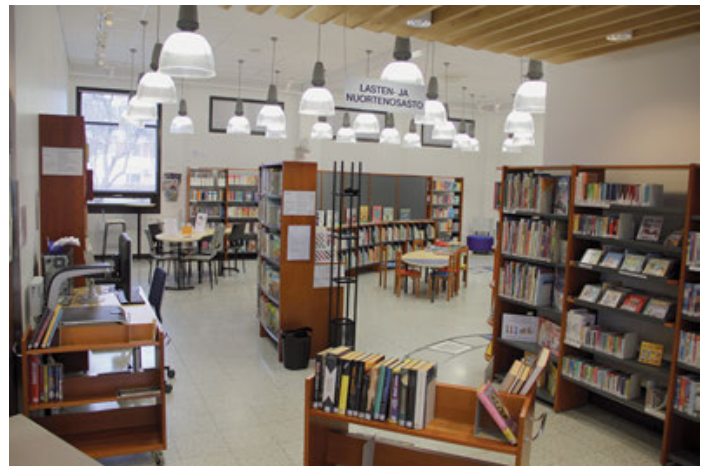

Fig. 7: Children's and young adults' department has different furnishings from elsewhere in the library. ( Eero Peltoniemi.

When the library moved into the new building, there was a supermarket in the neighbouring building. People visiting it passed the library and dropped in without planning to do so beforehand. Parents could easily leave children in the library while shopping. After a few years, the supermarket moved which caused a new challenge because the street beside the library became less busy and the number of casual customers decreased.

\section{The Librarians' Perspective}

Two members of library staff worked in the previous library building for some 20 years. The space was complicated with small rooms for different functions and different floor levels. Functional areas were located on two floors connected by a narrow and steep staircase and the staff facilities lay behind locked doors far 
from the library entrance. The new library has spacious staff facilities with even a changing room! Previously lockers were in the corridor and the cramped storage room offered some privacy for changing. Now there is a sink near the main desk and a storage space behind, not on the next floor. The new layout facilitates staffing the library with one person only.

The staff area, including kitchen, staff facilities, storeroom, offices and cleaners' store was entirely redesigned as a new floor plan was needed. The new offices and the cleaners' room are spacious. The location of the cleaners' room in the middle of the staff area is essential for incorporating the cleaning staff with the rest of the library staff. In the future, as staff numbers inevitably decrease, the head librarian's office can be incorporated into an open plan office and the private room can be used for other purposes. For example, telecommuting space can be offered for holidaymakers and those who want to move away from cities but keep working for the same employer.

Both the staff and the customers find it helpful that one to two years of back issues of magazines are easily available in customised shelving in the newspaper reading room (Figure 6). Magazines are widely borrowed and there is a good selection available. Finally it is possible to obtain full benefit from the magazine collection.

Audiovisual materials have an improved space allocation. In the old library the audiovisual material was little used as it was not obvious to users and the selection was poor. In the new library, the material is housed in movable towers which allows for more options as music, movies and audiobooks increasingly move into electronic formats.

The library space is flexible. For example, a new self-service point will soon be opened and no structural changes will be needed. Arranging different events such as authors' visits, nature photo shows or second-hand book sales is easy. After moving into the new library, the number of events and the participants in them have increased significantly as well as the number of customers in general. An ongoing second-hand book sale is a new service that can be provided within the new space.

The valuable Joutsa special collection of 640 items by local authors and musicians finally has a prominent, highly visible location. Previously, the collection was in cardboard boxes in the store so that the public did not even know that it existed. The availability of the collection has increased the appreciation of local talent.

The basement offers additional useful space for storage and houses part of the heating, ventilation and air conditioning system, with the rest in the attic. The additional space proved useful for housing the special collection of literary sports materials, donated to the Joutsa municipality by a local collector. The donation 
was made some years after the library moved into the new building and was not anticipated during the renovation project. The collection consists of 2,570 books, maps, newspapers, magazines and smaller items such as sport-themed stamps, letters and posters. Part of the collection is unique, for example posters of past local sports events. A meeting room for local organisations is also located in the basement.

New demands on the branch library are easy to accommodate within the new building. Secure and quiet spaces are available where private transactions such as registration can be carried out as well as new services required following digitisation and the increase of online information. E-learning classes and, for example, lessons on teaching the elderly how to use audiobooks are regularly held in the new meeting areas.

Cooperation between the architects and the library staff was excellent and functionality was prioritised from the very beginning. Barrier-free access was achieved throughout the building with automatic door and toilet access, ample space between the shelves and a ramp outside for wheelchair use.

\section{Further Reflections on the Outcomes of the Renovation}

According to a nationally conducted assessment of library spaces in 2009, the space occupied by library services, as well as the condition of those spaces, had been improving from 1999 to 2009 (Länsi- ja Sisä-Suomen aluehallintovirasto 2010). Still, there was variation between the municipalities. The availability of library service was limited by restricted opening hours, and a general reduction in service points. The library services were accessible only when the library staff were present. On a more positive note, the proximity of other services, both public and commercial, as well as cooperation between different sectors was an efficient way to increase the use of the library spaces. The main factors seen as in need of improvement were safety and physical accessibility of library spaces.

The recommendations given to the municipalities by the regional state administration consisted mainly of considering the needs of citizens and building cooperative networks between sectors to make the use of library space as efficient as possible. Advice was also given to monitor the status of building services closely, and to fix any defects quickly to prevent health hazards and, in a more bureaucratic economic sense, save tax-payers' money in construction and repair costs. 
At the time of the assessment, there were 27 municipalities in Central Finland, with $116 \mathrm{~m}^{2}$ of library space per thousand people. From 1999 until 2009 there had been a 4.2\% decrease in library service points in the whole of Western and Central Finland, as well as a 15.4\% decrease in the number of bookmobiles. Opening hours had decreased by $3.7 \%$ during the same period. Nationally, library service points had decreased by $9 \%$, bookmobiles by $23.6 \%$ and opening hours by $8.8 \%$ from 1999 to 2009 .

In Joutsa, the recommendations mentioned above were implemented. During the planning phase, cooperation between different sectors was undertaken and organisations and associations contacted and opinions and information sought. Particular attention was paid to physical accessibility and the organisations representing elderly people and those with disabilities were contacted. With the new building, opening hours increased which bucked the trend when compared to the situation of the whole country. And now, after 16 years, the opening hours will continue to increase as the self-service point will soon be opened.

\section{Conclusion}

Today, even after 16 years, the new library feels modern which shows that the architecture and design were successful. It is functional, open, warm and cosy and welcomes all kinds of customers.

The library puts the municipal strategy into practice. Joutsa is a lifelong partner of its citizens and everybody is taken care of. That is exactly what the library is about: it does not matter if one is young or old or unemployed or busy. Among modern trends is the desire to be less materialistic and another is to value the environment. Again, the library meets these aims and makes books, and much more, freely available for all to share. The building is sustainable, being both well-planned and constructed. The library tangibly supports the strategic objectives of the municipality such as community spirit by providing space for communal activities, and welfare and wellbeing by lending sports equipment and offering information. Libraries have always tried to anticipate social problems by providing safe spaces where people can connect, communicate, create or even just be together alone. An attractive, welcoming and functional building makes it possible to turn grand goals into reality. 


\section{Reference}

Länsi- ja Sisä-Suomen aluehallintovirasto. 2010. Peruspalvelut Länsi- ja Sisä-Suomen aluehallintoviraston toiminta-alueella 2009. 